\title{
Possibilities of pelvic floor electromyography in a woman after ischemic stroke
}

\section{- case report}

Kuba Ptaszkowski (Wrocław/PL), Lucyna Slupska (Opole/PL),

Robert Dymarek (Wroclaw/PL), Małgorzata Paprocka-Borowicz (Wrocław/PL)

\section{MATERIAL AND METHODS}

Study protocol

SURFACE ELECTROMYOGRAPHY -

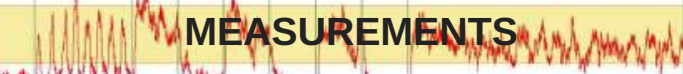

$$
\text { mavivisub twen the the }
$$

Baseline

\section{Quick flicks

Contractions

Static hold

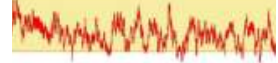

Rest tone

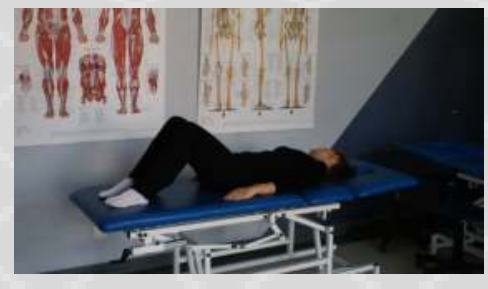

RESULTS

\begin{tabular}{|l|c|c|c|c|c|}
\hline & $\begin{array}{c}\text { Besline } \\
{[\mu \mathrm{V}]}\end{array}$ & $\begin{array}{c}\text { Quick Flicks } \\
{[\mu \mathrm{V}]}\end{array}$ & $\begin{array}{c}\text { Contractions } \\
{[\mu \mathrm{V}]}\end{array}$ & $\begin{array}{c}\text { Static Hold } \\
{[\mu \mathrm{V}]}\end{array}$ & $\begin{array}{c}\text { Rest tone } \\
{[\mu \mathrm{V}]}\end{array}$ \\
\hline Case 1 & 4.13 & 7.51 & 9.46 & 8.83 & 4.24 \\
\hline Case 2 & 2.56 & 7,77 & 9.38 & 5.90 & 1.60 \\
\hline
\end{tabular}

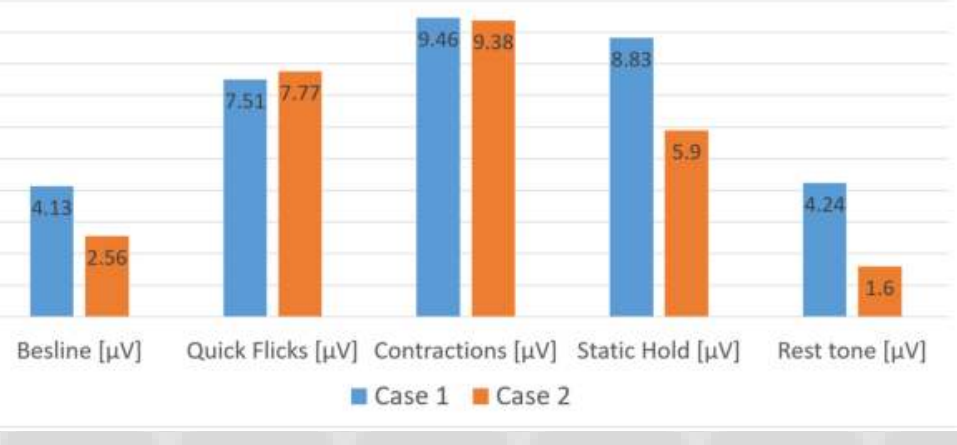

Research

equipment

Case 1: Woman (51 years old) 6 years after stroke. The patient suffered from symptoms of stress urinary incontinence

Case 2: Woman (50 years old) with stress urinary incontinence symptoms without a history of stroke

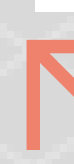
objective electromyographic assessment of pelvic floor muscles (PFM) and their ability to correct contraction in women after ischemic stroke with stress urinary incontinence (SUI).
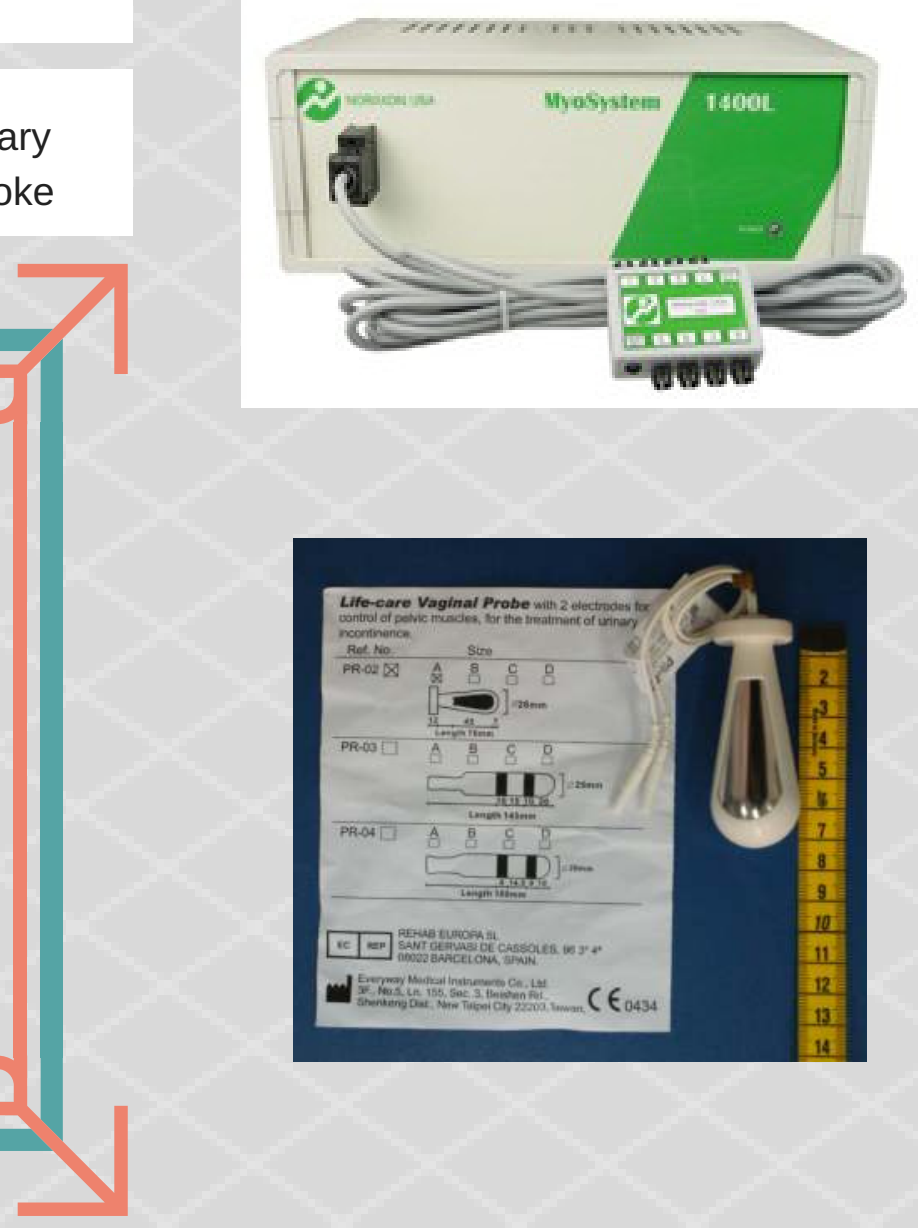

\section{GONGLUSION}

Despite the higher resting bioelectric activity of PFM in the woman after stroke, no higher activity of these muscles during contraction was observed. This may be a signal that the awareness and ability to

perform PFM contraction is lower in people after stroke. A full survey should be conducted on a representative sample of persons to verify this information. 